\title{
Household sanitation facilities and women's risk of non-partner sexual violence in India
}

\author{
Apoorva Jadhav ${ }^{1 *}$ (D) Abigail Weitzman ${ }^{1}$ and Emily Smith-Greenaway ${ }^{2}$
}

\begin{abstract}
Background: Globally, one in ten individuals practice open defecation. Despite media speculation that it increases women's risk of sexual violence, little empirical evidence supports the claims. We investigate the relationship between household sanitation facilities and women's risk of non-partner sexual violence (NPSV) in India, where nearly half of the population lives without a pit or toilet.

Methods: We use the most recent NPSV data, from the National Family Health Survey-III, to estimate logistic regression models of the effects of household sanitation facilities (toilet, pit, or none) on NPSV in the last year among women who have resided in their current home for one year or more. These effects are estimated net of other socioeconomic factors, compared to effects of household sanitation facilities on child diarrhea, and, as a falsification test, compared to effects of household sanitation facilities on intimate partner sexual violence (IPSV) in the last year.

Results: Net of their socioeconomic status, women who use open defecation are twice as likely to face NPSV as women with a household toilet. This is twice the association between open defecation and child diarrhea. The results of our falsification test indicate that open defecation is not correlated with IPSV, thus disconfirming a simultaneous selection of women into open defecation and sexual violence.
\end{abstract}

Conclusions: Our findings provide empirical evidence that lacking household sanitation is associated with higher risk of NPSV.

Keywords: Non-partner sexual violence, Rape, Sanitation, Defecation, Child health

\section{Background}

Nearly half of the world's population (42\%) continues to lack access to improved sanitation conditions, with more than one in ten $(13 \%)$ individuals forced to defecate in the open [1]. The majority of these individuals (59 \%) reside in India. Since 1990, the Indian government has introduced nationwide campaigns to improve sanitation facilities across the country-first under the Total Sanitation Campaign (TSC), and most recently under the Swachh Bharat Mission (SBM) [2]. However, the lack of improved sanitation remains a major public health concern $[1,3]$.

To date, public health research on open defecation has centered on its link to multiple infectious diseases, with a focus on its connection to ill health, particularly among

\footnotetext{
* Correspondence: anjadhav@umich.edu

'University of Michigan, 426 Thompson St, Ann Arbor, MI 48104, USA

Full list of author information is available at the end of the article
}

children, who are especially vulnerable to diarrhea-related morbidity [4, 5]. However, more recently, media has highlighted how poor sanitation extends beyond specific disease etiologies, suggesting that open defecation may put women at higher risk of NPSV [6]. Despite media accounts suggesting this link, scant empirical evidence exists., Qualitative research has linked women's lack of household sanitation and clean water sources to a heightened fear of sexual violence in India [7, 8], Vietnam [8], Kenya [9], and Ghana [10]. In the Indian state of Orissa, a majority of respondents feared unwanted sexual encounters such as being watched, indecent exposure, and NPSV. Another study confirmed that adolescent girls and young women-especially those residing in the local slum-were sexually victimized while accessing sanitation sources [11]. One recent study of women in Kenya linked open defecation to higher odds of NPSV [12]. 
We contribute to this body of literature by examining whether women's lack of household sanitary facilities is associated with a higher likelihood of experiencing NPSV. We use the most recent data available on sexual violence in India to test this relationship, estimating the effects net of other socioeconomic characteristics, and employing information from time-specific questions that ensure household sanitation facilities preceded violent incidents. We further rule out selection bias with a falsification test in which we use household sanitation facilities to predict intimate partner sexual violence (IPSV). To contextualize the magnitude of our findings, we conduct a parallel analysis of the relationship between household sanitation facilities and risk of waterborne illness, specifically, child diarrhea.

Our study is an important extension of research on violence against women, exploring a predictor of NPSV that is not well researched. While the data are from 2005-06, they are the most recently available data on sexual violence in India. Moreover, there is no reason to believe that the effects of open defecation on NPSV are period specific. We examine this association by joining two distinct literatures on sexual violence and water, sanitation and hygiene. It has been pointed out that discussions about making progress toward Millennium Development Goal (MDG) 7c - to "halve, by 2015, the proportion of the population without sustainable access to safe drinking water and basic sanitation" - have overlooked the importance of this goal for women's safety [13]. There is a critical need to understand the implications of sanitation facilities beyond the realm of illness. We argue that access to sanitation is a major factor in understanding sexual violence against women, and utilizing toilets may substantially mitigate some women's risk of NPSV.

\section{Methods}

We analyze data from the 2005-06 Indian National Family Health Survey- III (NFHS), a nationally representative dataset collected by ICF international and the Indian Ministry of Health using a stratified random sampling approach [14]. $68 \%$ of women from the full sample were selected for the domestic violence module, with one woman between the ages of 15 and 49 randomly selected from each household to answer questions about their exposure within the past year to different types of violence, including NPSV. Nearly all women agreed to participate in the module (99\%), which was administered in a private setting to help ensure accuracy of reports. We exclude the small percentage $(4 \% ; N=2,908)$ of women who had not resided in their current household for at least one year at the time of the survey, given that we have data on the sanitary facilities solely in women's current household. Because the measure of household sanitary facilities is at a single point in time, it is possible they changed over the course of the preceding year. The final analytic sample consists of 75,619 women.

To analyze the relationship between household sanitation facilities and NPSV, we classify women's household sanitation facilities into three categories: (1) toilet (i.e., flush, compost, and dry toilets), (2) pit/latrine, and (3) open defecation, which refers to respondents whose property does not contain any type of sanitation facility. We distinguish sexual violence from physical violence using World Health Organization (WHO) definitions. They define physical violence - being pushed, kicked, shoved, dragged on purpose - largely in the realm of intimate partner violence (IPV), while non partner violence is defined largely by sexual violence. Specifically, as any woman aged 15 and over being forced to perform any sexual act that they did not want, by someone other than husband or partner [15]. Our measure of NPSV is based on responses to two questions. First, all women were asked: "At any time in your life, as a child or as an adult, has anyone ever forced you in any way to have sexual intercourse or perform any other sexual acts?" Never-married respondents who replied "yes" were then asked: "In the last twelve months, has anyone forced you to have sexual intercourse or perform any other sexual acts against your will?" Ever-married respondents who replied "yes" were asked the same question but were specifically asked whether "anyone other than your (current/ last) husband" had forced them to perform such acts. 'Yes' answers from both never- and ever-married respondents are coded 1; 'no' answers for ever experiencing sexual violence or for experiencing sexual violence from someone other than a husband in the prior twelve months are coded 0 . Twelve respondents refused to answer the question and are omitted from the analysis $(<0 \cdot 01 \%$ of the sample). No information about the perpetrators, or report of NPSV to authorities, or severity of attack was asked in this survey, which would have added to our understanding of NPSV in India.

We begin our investigation with a bivariate analysis of household sanitation facilities and NPSV. We then conduct a multivariate analysis that adjusts for respondents' demographic characteristics, including number of years of education (0-23); age (15-49 years); relationship status (never married, married, widowed, not living together); caste and religion (upper caste Hindu; scheduled caste/tribe Hindu; other backward caste Hindu; lower class Muslim; forward class Muslim; other scheduled caste/tribe, Christian, or Buddhist; and other); level of urbanization (mega city, large city, small city, large town, small town, rural); and geographic region (North, North-central, North-east, East, West, and South). Last, we rerun our multivariate model of NPSV adjusting for both demographic characteristics and household assets, 
which are characterized using both a dummy for electricity and a categorical measure of roof material (natural; man-made and semi-permanent; and man-made and permanent). Because NPSV is measured dichotomously, we use logistic regressions to conduct all bivariate and multivariate analyses.

We estimate two parallel sets of analyses. First, to put the magnitude of our estimated associations of the relationship between women's access to sanitation facilities and NPSV in perspective, we test the relationship between household sanitation facilities and diarrhea among children. This analysis is limited to mothers with a child younger than age five residing in their same household $(N=25,285 ; 33 \%$ of the analytic sample). Among respondents with children of this age, those who report that at least one child has had diarrhea within the preceding two weeks are coded (1) for "at least one child sick"; those who report that no child has had diarrhea within the preceding two weeks are coded (0) for "none." Among this sample of respondents, the proportions reporting at least one young child with diarrhea are $10 \%$ (95\% CI 0.09-0.10) for those using a toilet, $13 \%$ (95\% CI 0.11-0 14) for those using a pit/latrine, and $12 \%(95 \% \mathrm{CI} 0 \cdot 11-0 \cdot 13)$ for those using open defecation (bivariate analysis not shown).

Second, to address whether the observed associations with NPSV reflect the selection of disadvantaged women into both households that lack sanitation facilities and higher risk of sexual violence, or are specific only to NPSV, we explore whether lack of sanitation facilities is also associated with IPSV. Though we account for socioeconomic factors in our main analyses, we recognize that other unobserved factors could drive a spurious association between household sanitation facilities and sexual violence. However, if this were the case, we would also anticipate to observe an association between household sanitation facilities and IPSV. Because there is no reason to believe there is a direct association between household sanitation facilities and IPSV, documenting such an association would suggest our findings are spurious. However, finding no direct association between sanitation and IPSV would strengthen support that any observed association between household sanitation facilities and NPSV reflects a non-spurious process. Among the full sample, proportions reporting IPSV in the prior 12 months are $5 \%$ (95\% CI 0.04-0.05) for those using a toilet and $8 \%$ for those using either a pit/latrine $(95 \%$ CI $0 \cdot 07-0 \cdot 09)$ or open defecation (95\% CI: 0 07-0 - 08).

In our analyses of both child diarrhea, and IPSV, we adjust for the same demographic characteristics and household assets as our most saturated model of NPSV. All analyses are weighted to provide nationally representative estimates. For ease of interpretation, we present the results of all logistic regressions in terms of oddsratios (Tables 2, 3 and 4).

\section{Results}

Only $53 \%$ (95\% CI $0 \cdot 52-0 \cdot 53)$ of respondents in our sample have access to sanitation facilities in the household; 8 \% (95 \% CI 0.08-0.08) use pits/latrines; and $39 \%(95 \%$ CI $0 \cdot 38-0 \cdot 39)$ use open defecation (univariate analysis not shown). As shown in Fig. 1, women's access to household sanitation facilities varies substantially across regions of India. For instance, in Northeast India, only $10 \%(95 \%$ CI $0 \cdot 10-0 \cdot 11)$ of respondents defecate in the open compared to $50 \%$ (95\% CI 0.49-0.50) of respondents in East India.

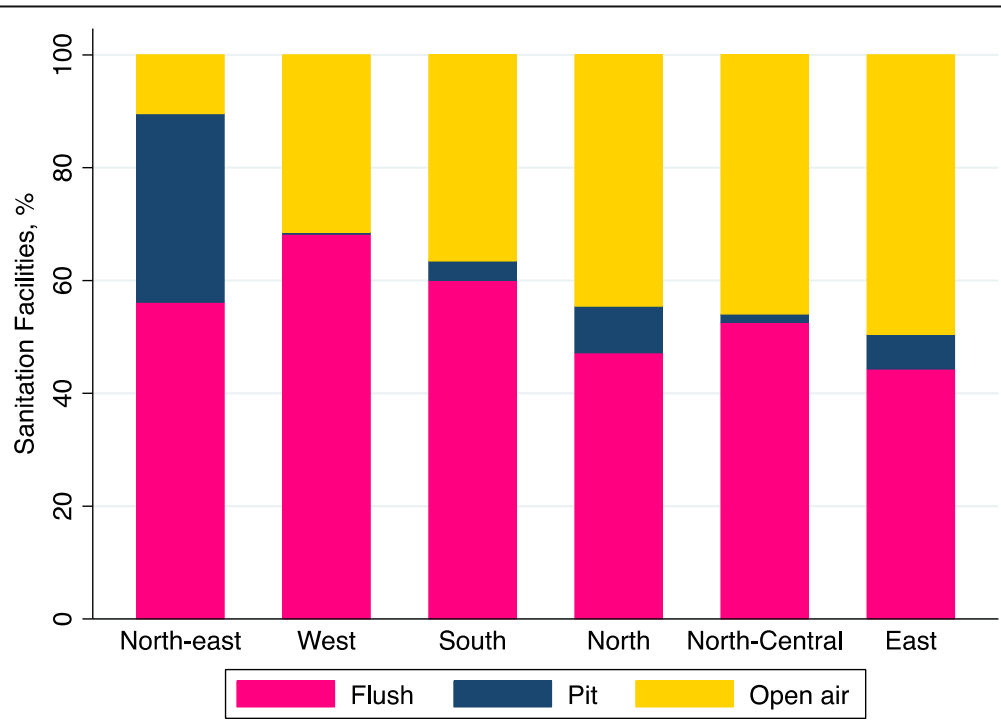

Fig. 1 Percentage households with flush toilet, pit latrine, or reliance on open air defecation in India, by region ( $N=75,619$ households) 
As presented in Table 1, NPSV is rare in the Indian context. According to our estimates, $0.1 \%(95 \% \mathrm{CI}$ 0.001-0.001) of respondents using toilets, $0.1 \%$ (95\% CI 0.0004-0.002) of respondents using pits/ latrines, and $0 \cdot 2 \%$ (95\% CI 0 001-0 002) of respondents using open defecation had experienced NPSV in the prior year. Despite its rarity, our descriptive analysis indicates that NPSV is twice as common among women using open defecation than it is among women using toilets (t-tests confirm this difference; $p<0.05$ ), though we

Table 1 Sample characteristics of Indian Women, by their household's sanitation facilities (2005-06), N=75,619 women

\begin{tabular}{|c|c|c|c|c|c|c|}
\hline & \multicolumn{2}{|l|}{ Toilet } & \multicolumn{2}{|c|}{ Pit/ latrine } & \multicolumn{2}{|c|}{ Open air } \\
\hline & Mean & $(95 \% \mathrm{Cl})$ & Mean & $(95 \% \mathrm{Cl})$ & Mean & $(95 \% \mathrm{Cl})$ \\
\hline \multicolumn{7}{|l|}{ Outcomes } \\
\hline Non-partner sexual violence within 12 months & $0 \cdot 001$ & $(0 \cdot 001-0 \cdot 001)$ & $0 \cdot 001$ & $(0 \cdot 0004-0 \cdot 002)$ & $0 \cdot 002$ & $(0.001-0.002)$ \\
\hline \multicolumn{7}{|l|}{ Respondent's demographic characteristics } \\
\hline Education (years) & $7 \cdot 75$ & $(7 \cdot 71-7 \cdot 80)$ & $4 \cdot 96$ & $(4 \cdot 85-5 \cdot 07)$ & $2 \cdot 45$ & $(2 \cdot 41-2 \cdot 49)$ \\
\hline Age (years) & $30 \cdot 77$ & $(30 \cdot 69-30 \cdot 86)$ & $29 \cdot 87$ & $(29 \cdot 66-30 \cdot 09)$ & $29 \cdot 83$ & $(29 \cdot 73-29 \cdot 93)$ \\
\hline \multicolumn{7}{|l|}{ Relationship status } \\
\hline Never married & $0 \cdot 18$ & $(0 \cdot 17-0 \cdot 18)$ & $0 \cdot 15$ & $(0 \cdot 14-0 \cdot 16)$ & $0 \cdot 11$ & $(0 \cdot 11-0 \cdot 12)$ \\
\hline Married & $0 \cdot 79$ & $(0 \cdot 78-0 \cdot 79)$ & $0 \cdot 81$ & $(0 \cdot 80-0 \cdot 82)$ & $0 \cdot 83$ & $(0 \cdot 83-0 \cdot 84)$ \\
\hline Widowed & $0 \cdot 03$ & $(0 \cdot 03-0 \cdot 03)$ & $0 \cdot 03$ & $(0 \cdot 02-0 \cdot 03)$ & $0 \cdot 04$ & $(0 \cdot 04-0 \cdot 04)$ \\
\hline Not living together & $0 \cdot 01$ & $(0.01-0.01)$ & $0 \cdot 02$ & $(0.01-0.02)$ & $0 \cdot 01$ & $(0 \cdot 01-0.02)$ \\
\hline \multicolumn{7}{|l|}{ Caste/ religion } \\
\hline Upper Caste Hindu & $0 \cdot 34$ & $(0 \cdot 34-0 \cdot 35)$ & $0 \cdot 25$ & $(0 \cdot 24-0 \cdot 26)$ & $0 \cdot 14$ & $(0 \cdot 14-0 \cdot 14)$ \\
\hline SC/ST Hindu & $0 \cdot 14$ & $(0 \cdot 14-0 \cdot 14)$ & $0 \cdot 18$ & $(0 \cdot 17-0 \cdot 19)$ & $0 \cdot 33$ & $(0 \cdot 33-0.34)$ \\
\hline OBC Hindu & $0 \cdot 28$ & $(0 \cdot 27-0 \cdot 28)$ & $0 \cdot 19$ & $(0 \cdot 18-0 \cdot 20)$ & $0 \cdot 40$ & $(0 \cdot 39-0 \cdot 40)$ \\
\hline Lower class Muslim & $0 \cdot 06$ & $(0 \cdot 06-0 \cdot 06)$ & $0 \cdot 04$ & $(0.03-0.04)$ & $0 \cdot 04$ & $(0.04-0.04)$ \\
\hline Forward class Muslim & $0 \cdot 10$ & $(0 \cdot 09-0 \cdot 10$ & $0 \cdot 25$ & $(0 \cdot 24-0 \cdot 26)$ & $0 \cdot 05$ & $(0 \cdot 05-0 \cdot 06)$ \\
\hline Other SC/ST, Christian, Buddhist & $0 \cdot 04$ & $(0.03-0.04)$ & $0 \cdot 05$ & $(0.05-0.06)$ & $0 \cdot 02$ & $(0.02-0.02)$ \\
\hline Other & $0 \cdot 05$ & $(0 \cdot 05-0 \cdot 05)$ & $0 \cdot 04$ & $(0 \cdot 04-0 \cdot 05)$ & $0 \cdot 02$ & $(0 \cdot 02-0 \cdot 02)$ \\
\hline \multicolumn{7}{|l|}{ City size } \\
\hline Mega city & $0 \cdot 08$ & $(0 \cdot 08-0 \cdot 08)$ & $0 \cdot 004$ & $(0 \cdot 002-0 \cdot 01)$ & $0 \cdot 001$ & $(0.001-0.002)$ \\
\hline Large city & $0 \cdot 17$ & $(0 \cdot 17-0 \cdot 18)$ & $0 \cdot 05$ & $(0.04-0.05)$ & $0 \cdot 01$ & $(0.01-0.01)$ \\
\hline Small city & $0 \cdot 18$ & $(0 \cdot 17-0 \cdot 18)$ & $0 \cdot 05$ & $(0 \cdot 05-0 \cdot 06)$ & $0 \cdot 02$ & $(0 \cdot 02-0.03)$ \\
\hline Large town & $0 \cdot 04$ & $(0 \cdot 04-0 \cdot 05)$ & $0 \cdot 02$ & $(0 \cdot 02-0 \cdot 02)$ & $0 \cdot 01$ & $(0 \cdot 01-0 \cdot 01)$ \\
\hline Small town & $0 \cdot 17$ & $(0 \cdot 17-0 \cdot 17)$ & $0 \cdot 11$ & $(0 \cdot 10-0 \cdot 12)$ & $0 \cdot 06$ & $(0 \cdot 05-0 \cdot 06)$ \\
\hline Rural & $0 \cdot 35$ & $(0 \cdot 35-0 \cdot 36)$ & $0 \cdot 77$ & $(0 \cdot 76-0 \cdot 78)$ & $0 \cdot 90$ & $(0 \cdot 90-0 \cdot 90)$ \\
\hline \multicolumn{7}{|l|}{ Geographic region } \\
\hline North & $0 \cdot 11$ & $(0 \cdot 11-0 \cdot 11)$ & $0 \cdot 12$ & $(0 \cdot 11-0 \cdot 13)$ & $0 \cdot 11$ & $(0 \cdot 10-0 \cdot 11)$ \\
\hline North- central & $0 \cdot 23$ & $(0 \cdot 23-0 \cdot 24)$ & $0 \cdot 13$ & $(0 \cdot 12-0 \cdot 14)$ & $0 \cdot 35$ & $(0 \cdot 35-0 \cdot 36)$ \\
\hline North- east & $0 \cdot 04$ & $(0 \cdot 04-0 \cdot 04)$ & $0 \cdot 32$ & $(0 \cdot 30-0 \cdot 33)$ & $0 \cdot 01$ & $(0 \cdot 01-0 \cdot 02)$ \\
\hline East & $0 \cdot 13$ & $(0 \cdot 13-0 \cdot 14)$ & $0 \cdot 26$ & $(0 \cdot 25-0 \cdot 27)$ & $0 \cdot 19$ & $(0 \cdot 18-0 \cdot 19)$ \\
\hline West & $0 \cdot 21$ & $(0 \cdot 20-0 \cdot 21)$ & $0 \cdot 01$ & $(0 \cdot 01-0 \cdot 02)$ & $0 \cdot 12$ & $(0 \cdot 12-0 \cdot 13)$ \\
\hline South & $0 \cdot 28$ & $(0 \cdot 27-0 \cdot 28)$ & $0 \cdot 16$ & $(0 \cdot 15-0 \cdot 17)$ & $0 \cdot 22$ & $(0 \cdot 21-0 \cdot 22)$ \\
\hline \multicolumn{7}{|l|}{ Household Assets } \\
\hline Has electricity in house & $0 \cdot 92$ & $(0.92-0.92)$ & $0 \cdot 61$ & $(0 \cdot 60-0.62)$ & $0 \cdot 52$ & $(0.52-0.53)$ \\
\hline \multicolumn{7}{|l|}{ Roof material } \\
\hline Natural & $0 \cdot 06$ & $(0 \cdot 06-0 \cdot 06)$ & $0 \cdot 20$ & $(0 \cdot 19-0 \cdot 21)$ & $0 \cdot 32$ & $(0 \cdot 32-0.33)$ \\
\hline Man- made, semi- permanent & $0 \cdot 18$ & $(0 \cdot 18-0 \cdot 19)$ & $0 \cdot 40$ & $(0 \cdot 39-0 \cdot 41)$ & $0 \cdot 16$ & $(0 \cdot 15-0 \cdot 16)$ \\
\hline Man- made, permanent & $0 \cdot 75$ & $(0 \cdot 75-0 \cdot 76)$ & $0 \cdot 40$ & $(0 \cdot 39-0 \cdot 41)$ & $0 \cdot 52$ & $(0.52-0.53)$ \\
\hline
\end{tabular}


Table 2 Logistic regression model results of the association between Indian women's household sanitation facilities and their experience of NPV within the last twelve months (2005-06), $N=75,619$

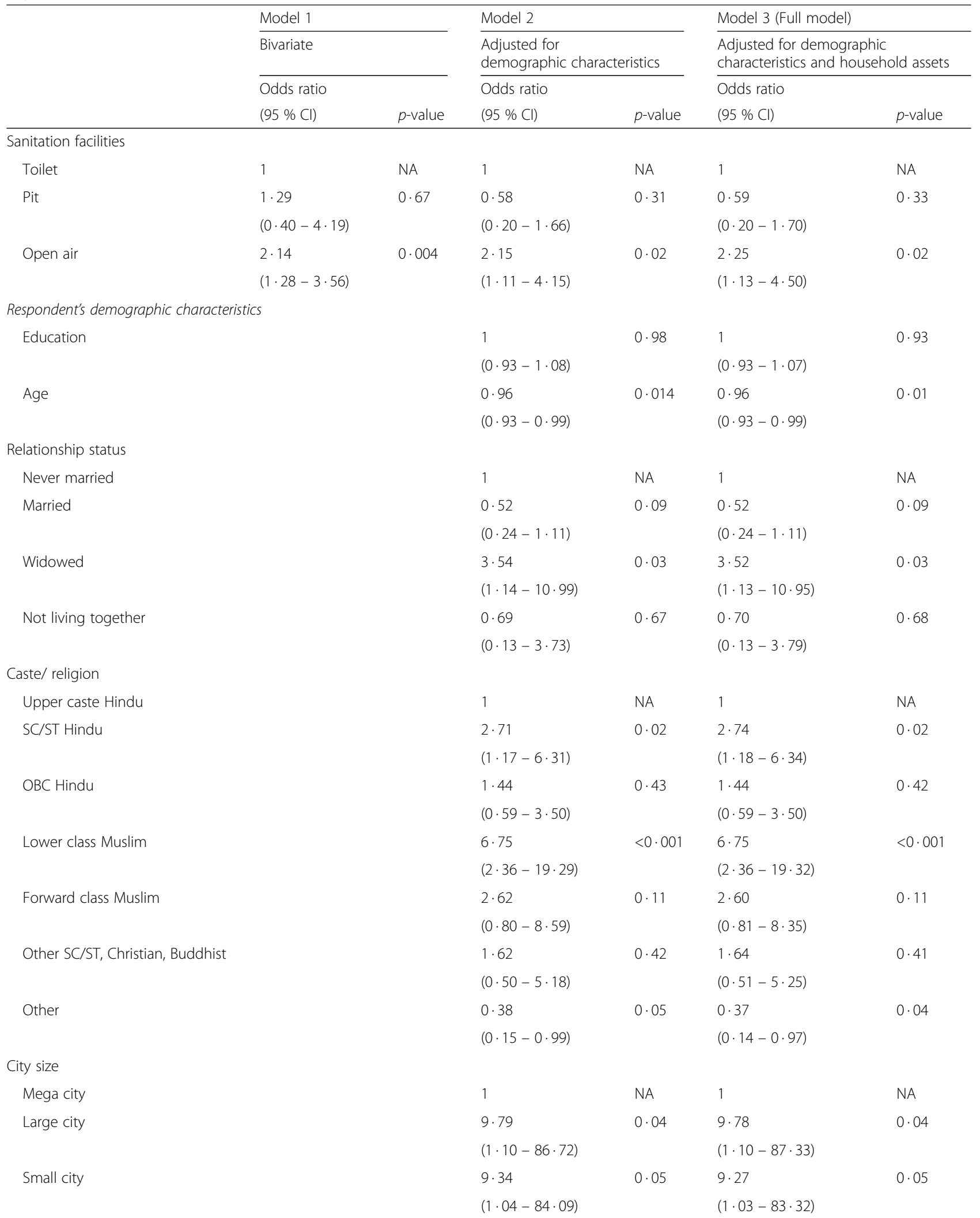


Table 2 Logistic regression model results of the association between Indian women's household sanitation facilities and their experience of NPV within the last twelve months (2005-06), $N=75,619$ (Continued)

\begin{tabular}{|c|c|c|c|c|c|}
\hline \multirow[t]{2}{*}{ Large town } & & $11 \cdot 28$ & $0 \cdot 07$ & $11 \cdot 16$ & $0 \cdot 08$ \\
\hline & & $(0 \cdot 80-159 \cdot 48)$ & & $(0 \cdot 78-160 \cdot 26)$ & \\
\hline \multirow[t]{2}{*}{ Small town } & & $7 \cdot 95$ & $0 \cdot 05$ & $7 \cdot 95$ & $0 \cdot 05$ \\
\hline & & $(0 \cdot 97-65 \cdot 07)$ & & $(0 \cdot 97-65 \cdot 40)$ & \\
\hline \multirow[t]{2}{*}{ Rural } & & $7 \cdot 46$ & $0 \cdot 06$ & $7 \cdot 55$ & $0 \cdot 06$ \\
\hline & & $(0 \cdot 93-59 \cdot 77)$ & & $(0 \cdot 95-60 \cdot 31)$ & \\
\hline \multicolumn{6}{|l|}{ Geographic region } \\
\hline North & & 1 & NA & 1 & NA \\
\hline \multirow[t]{2}{*}{ North-central } & & $0 \cdot 92$ & $0 \cdot 85$ & $0 \cdot 90$ & $0 \cdot 82$ \\
\hline & & $(0 \cdot 40-2 \cdot 12)$ & & $(0 \cdot 39-2 \cdot 11)$ & \\
\hline \multirow[t]{2}{*}{ North-east } & & $4 \cdot 64$ & $0 \cdot 002$ & $4 \cdot 22$ & $0 \cdot 01$ \\
\hline & & $(1 \cdot 77-12 \cdot 20)$ & & $(1 \cdot 41-12 \cdot 63)$ & \\
\hline \multirow[t]{2}{*}{ East } & & $0 \cdot 98$ & $0 \cdot 97$ & $0 \cdot 90$ & $0 \cdot 81$ \\
\hline & & $(0 \cdot 42-2 \cdot 30)$ & & $(0 \cdot 38-2 \cdot 14)$ & \\
\hline \multirow[t]{2}{*}{ West } & & $0 \cdot 86$ & $0 \cdot 78$ & $0 \cdot 76$ & $0 \cdot 61$ \\
\hline & & $(0 \cdot 28-2 \cdot 58)$ & & $(0 \cdot 26-2 \cdot 22)$ & \\
\hline \multirow[t]{2}{*}{ South } & & $0 \cdot 60$ & $0 \cdot 34$ & $0 \cdot 58$ & $0 \cdot 30$ \\
\hline & & $(0 \cdot 22-1 \cdot 69)$ & & $(0 \cdot 21-1 \cdot 60)$ & \\
\hline \multicolumn{6}{|l|}{ Household assets } \\
\hline \multicolumn{2}{|l|}{ Electricity in home } & & & $0 \cdot 95$ & $0 \cdot 86$ \\
\hline \multicolumn{2}{|l|}{ Roof material } & & & $(0 \cdot 51-1 \cdot 75)$ & \\
\hline \multicolumn{2}{|l|}{ Natural } & & & 1 & NA \\
\hline \multirow[t]{2}{*}{ Man-made, semi-permanent } & & & & $1 \cdot 65$ & $0 \cdot 26$ \\
\hline & & & & $(0 \cdot 69-3 \cdot 93)$ & \\
\hline \multirow[t]{2}{*}{ Man-made, permanent } & & & & $1 \cdot 54$ & $0 \cdot 23$ \\
\hline & & & & $(0 \cdot 77-3 \cdot 08)$ & \\
\hline \multirow[t]{2}{*}{ Constant } & $<0 \cdot 001$ & $0 \cdot 0003$ & $<0 \cdot 001$ & $0 \cdot 0002$ & $<0 \cdot 001$ \\
\hline & $(0 \cdot 001-0.001)$ & $(0.00003-0.003)$ & & $(0 \cdot 00002-0.003)$ & \\
\hline
\end{tabular}

Note. $95 \% \mathrm{Cl}$ in parentheses

found no statistically significant difference in risk of NPSV among women using pits/latrines versus open defecation (analysis not shown).

The logistic regression model results shown for Model 1 of Table 2 confirm a significant association between household sanitary facilities and NPSV. Compared to women who have access to a toilet in their household, Indian women who must open defecate have 2.14 times the risk of NPSV $(p<.01)$. The results for Model $2-$ which includes the demographic, geographic, and socioeconomic factors - confirm the association is robust, though the strength of the association is slighted attenuated $(p<.05)$. The results for Model 3 - which adds in measures of household assets and infrastructure - also support the significant association between open defecation and NPSV. Analysis including interaction terms with demographic and socioeconomic correlates was not significant.
To put the magnitude of this association in perspective, Table 3 presents the results of a parallel analysis of household sanitation facilities and young children's recent diarrhea (within two weeks preceding survey). Households that lack sanitary facilities have higher burdens of child diarrhea compared to households with a flushed toilet. We found that, compared to their peers who live in a house with a flush toilet, households using a pit/latrine or open defecation have $44 \%$ and $27 \%$ higher odds of having children with diarrheal disease, respectively. Although it is large and significant, the association between sanitation facilities and child diarrhea is only about one-fourth the size of the one between household sanitation facilities and NPSV, demonstrating the strength of the relationship with NPSV.

It is possible that Indian women who lack adequate household sanitation facilities share other traits that 
Table 3 Logistic regression model results of the association between household sanitary facilities and diarrhea among children under age five within the two weeks preceding the survey in India (2005-06), N=25,285

\begin{tabular}{lll}
\hline & Odds ratio & \\
\cline { 2 - 3 }$(95 \% \mathrm{Cl})$ & $p$-value \\
\hline
\end{tabular}

Sanitation facilities

Toilet

Pit

1

$1 \cdot 44$

NA

$(1 \cdot 11-1 \cdot 86)$

Open air

$1 \cdot 27$

$0 \cdot 004$

$(1 \cdot 08-1 \cdot 49)$

Respondent's demographic characteristics

Education

$1 \cdot 00$

Age

$(0 \cdot 99-1 \cdot 01)$

0.97

$(0 \cdot 96-0 \cdot 98)$

Relationship status

Never married

Married

Widowed

Not living together

1

$5 \cdot 60$

$(1 \cdot 45-21 \cdot 70)$

$3 \cdot 40$

$(0 \cdot 73-15 \cdot 79)$

$4 \cdot 57$

$(0 \cdot 95-21 \cdot 94)$

Caste/ religion

Upper caste Hindu

SC/ST Hindu

OBC Hindu

Lower class Muslim

Other SC/ST, Christian, Buddhist

Other

City size

Mega city

Large city

Small city

Large town

1 NA

$1 \cdot 13$

$(0 \cdot 95-1 \cdot 35)$

$1 \cdot 23$

$(1.03-1 \cdot 47)$

$1 \cdot 59$

$(1 \cdot 23-2 \cdot 05)$

$1 \cdot 40$

$(1 \cdot 12-1 \cdot 76)$

$1 \cdot 48$

$(1 \cdot 06-2 \cdot 05)$

$1 \cdot 31$

$(0 \cdot 97-1 \cdot 76)$

$1 \cdot 11$

$(0 \cdot 78-1 \cdot 58)$

$1 \cdot 35$

$(0.96-1 \cdot 90)$

$1 \cdot 77$
Table 3 Logistic regression model results of the association between household sanitary facilities and diarrhea among children under age five within the two weeks preceding the survey in India (2005-06), N=25,285 (Continued)

\begin{tabular}{|c|c|c|}
\hline & $(1 \cdot 15-2 \cdot 73)$ & \\
\hline \multirow[t]{2}{*}{ Small town } & $1 \cdot 15$ & $0 \cdot 45$ \\
\hline & $(0 \cdot 81-1 \cdot 63)$ & \\
\hline \multirow[t]{2}{*}{ Rural } & $1 \cdot 19$ & $0 \cdot 26$ \\
\hline & $(0 \cdot 88-1 \cdot 61)$ & \\
\hline \multicolumn{3}{|l|}{ Geographic region } \\
\hline North & 1 & NA \\
\hline \multirow[t]{2}{*}{ North-central } & $1 \cdot 12$ & $0 \cdot 29$ \\
\hline & $(0 \cdot 91-1 \cdot 37)$ & \\
\hline \multirow[t]{2}{*}{ North-east } & $0 \cdot 89$ & $0 \cdot 44$ \\
\hline & $(0 \cdot 65-1 \cdot 21)$ & \\
\hline \multirow[t]{2}{*}{ East } & $0 \cdot 89$ & $0 \cdot 27$ \\
\hline & $(0 \cdot 72-1 \cdot 10)$ & \\
\hline \multirow[t]{2}{*}{ West } & $1 \cdot 13$ & $0 \cdot 30$ \\
\hline & $(0 \cdot 90-1 \cdot 43)$ & \\
\hline \multirow[t]{2}{*}{ South } & $0 \cdot 59$ & $<0 \cdot 001$ \\
\hline & $(0 \cdot 47-0 \cdot 74)$ & \\
\hline \multicolumn{3}{|l|}{ Household assets } \\
\hline Electricity in home & $1 \cdot 08$ & $0 \cdot 34$ \\
\hline Roof material & $(0 \cdot 92-1 \cdot 26)$ & \\
\hline Natural & 1 & NA \\
\hline \multirow[t]{2}{*}{ Man-made, semi-permanent } & $0 \cdot 89$ & $0 \cdot 31$ \\
\hline & $(0 \cdot 72-1 \cdot 11)$ & \\
\hline \multirow[t]{2}{*}{ Man-made, permanent } & $1 \cdot 05$ & $0 \cdot 59$ \\
\hline & $(0 \cdot 89-1 \cdot 23)$ & \\
\hline \multirow[t]{2}{*}{ Constant } & $0 \cdot 03$ & $<0 \cdot 001$ \\
\hline & $(0 \cdot 01-0 \cdot 14)$ & \\
\hline
\end{tabular}

Note. $95 \% \mathrm{Cl}$ in parentheses

drive their higher risk of both living in a household without sanitary facilities and sexual violence. If this is the case, we expect there to be a comparable association between household sanitary facilities and IPSV within the prior year (Table 4). That is, a significant association between household sanitation facilities and IPSV-two factors not theoretically related-would suggest that our sanitation-NPSV results are likely due to some unmeasured characteristics or processes. We find no evidence that open defecation is significantly associated with an elevated risk of IPSV, lending support to the conclusion that open defecation places women at uniquely higher risk of one type of sexual violence: non-partner.

\section{Discussion}

The separate issues of household sanitation and women's risk of sexual violence in India have received substantial 
Table 4 Logistic regression model results of the association between household sanitary facilities and IPV within the 12 months preceding the survey in India (2005-06), $N=58,584$

\begin{tabular}{ll}
\hline $\begin{array}{l}\text { Adjusted for demographic } \\
\text { and partner characteristics, } \\
\text { and household assets }\end{array}$ \\
\cline { 2 - 2 } Odds ratio $(95 \% \mathrm{Cl}) \quad p$-value \\
\hline
\end{tabular}

\begin{tabular}{lll}
\hline Sanitation facilities & & \\
Toilet & & NA \\
Pit & 0.79 & 0.032 \\
& $(0 \cdot 63-0 \cdot 98)$ & \\
Open air & $1 \cdot 00$ & 0.966 \\
& $(0.85-1 \cdot 18)$ &
\end{tabular}

Respondent's demographic characteristics

$\begin{array}{ll}\text { Education } & 0.96 \\ & (0.95-0 \cdot 98) \\ \text { Age } & 0.96 \\ & (0.95-0 \cdot 98)\end{array}$

Caste/religion

Upper Caste Hindu

SC/ST Hindu

1

$1 \cdot 08$

$(0 \cdot 92-1 \cdot 26)$

OBC Hindu

0.98

$(0 \cdot 84-1 \cdot 16)$

Lower class Muslim

0.74

$(0 \cdot 56-0 \cdot 99)$

Forward class Muslim

$1 \cdot 41$

$(1 \cdot 11-1 \cdot 78)$

Other SC/ST, Christian, Buddhist

$0 \cdot 72$

$(0 \cdot 51-1 \cdot 03)$

Other

0.64

$(0 \cdot 45-0 \cdot 90)$

City size

Mega city

Large city

1

$2 \cdot 51$

$(1 \cdot 68-3 \cdot 76)$

Small city

$1 \cdot 87$

$(1 \cdot 25-2 \cdot 80)$

Large town

$4 \cdot 14$

$(2 \cdot 62-6 \cdot 55)$

Small town

$1 \cdot 96$

$(1 \cdot 30-2 \cdot 96)$

Rural

$2 \cdot 20$

$(1 \cdot 55-3 \cdot 14)$

Geographic region

North
Table 4 Logistic regression model results of the association between household sanitary facilities and IPV within the 12 months preceding the survey in India (2005-06), $N=58,584$ (Continued)

\begin{tabular}{|c|c|c|}
\hline \multirow[t]{2}{*}{ North-central } & $0 \cdot 83$ & $0 \cdot 120$ \\
\hline & $(0 \cdot 66-1 \cdot 05)$ & \\
\hline \multirow[t]{2}{*}{ North-east } & $1 \cdot 18$ & $0 \cdot 260$ \\
\hline & $(0 \cdot 88-1 \cdot 58)$ & \\
\hline \multirow[t]{2}{*}{ East } & $1 \cdot 25$ & $0 \cdot 055$ \\
\hline & $(1 \cdot 00-1 \cdot 58)$ & \\
\hline \multirow[t]{2}{*}{ West } & $0 \cdot 27$ & $<0 \cdot 001$ \\
\hline & $(0 \cdot 20-0 \cdot 36)$ & \\
\hline \multirow[t]{2}{*}{ South } & $0 \cdot 31$ & $<0 \cdot 001$ \\
\hline & $(0 \cdot 24-0 \cdot 40)$ & \\
\hline \multicolumn{3}{|l|}{ Partner and couple characteristics } \\
\hline \multirow[t]{2}{*}{ Education } & $0 \cdot 98$ & $<0 \cdot 001$ \\
\hline & $(0 \cdot 96-0 \cdot 99)$ & \\
\hline \multirow[t]{2}{*}{ Age } & $1 \cdot 00$ & $0 \cdot 854$ \\
\hline & $(0 \cdot 99-1 \cdot 01)$ & \\
\hline \multirow[t]{2}{*}{ Fertility } & $1 \cdot 04$ & $0 \cdot 016$ \\
\hline & $(1 \cdot 01-1 \cdot 07)$ & \\
\hline \multirow[t]{2}{*}{ Husband does not live at home } & $1 \cdot 07$ & $0 \cdot 520$ \\
\hline & $(0 \cdot 88-1 \cdot 29)$ & \\
\hline \multicolumn{3}{|l|}{ Household assets } \\
\hline \multirow[t]{2}{*}{ Electricity in home } & $0 \cdot 96$ & $0 \cdot 595$ \\
\hline & $(0 \cdot 84-1 \cdot 10)$ & \\
\hline \multicolumn{3}{|l|}{ Roof material } \\
\hline Natural & 1 & \\
\hline \multirow[t]{2}{*}{ Man-made, semi-permanent } & $0 \cdot 96$ & $<0 \cdot 001$ \\
\hline & $(0 \cdot 81-1 \cdot 14)$ & \\
\hline \multirow[t]{2}{*}{ Man-made, permanent } & $0 \cdot 95$ & $0 \cdot 448$ \\
\hline & $(0 \cdot 82-1 \cdot 09)$ & \\
\hline \multirow[t]{2}{*}{ Constant } & $0 \cdot 19$ & $<0 \cdot 001$ \\
\hline & $(0 \cdot 000-0 \cdot 12)$ & \\
\hline
\end{tabular}

Note. $95 \% \mathrm{Cl}$ in parentheses

attention from both scholars and policymakers in recent years $[11,16]$. However, little research has asked whether the two issues are linked. Reliable statistics on NPSV are likely to be downward biased due to underreporting, particularly in the South Asian context, however, a systematic review found that $3.3 \%$ of women in India and Bangladesh reported this type of violence - distinct from IPSV [17]. Non-profits dedicated to improving sanitation and water projects around the world have begun to include gender and violence components in their agenda $[18,19]$. Though this suggests an increasing awareness of the link between NPSV and household sanitation, much more empirical research is needed on 
this topic. Additionally, improving a household's sanitary conditions is not necessarily the solution to minimizing NPSV. Studies have shown that about $50 \%$ of toilets built by Indian governmental programs are not used for their intended purpose $[4,20]$, and at least one study suggests that in North India, many people prefer open defecation to toilet use [21]. For toilets to protect women against NPSV, they must be used in place of open defecation. Improving the social acceptability of toilet use is thus imperative, and our study provides concrete evidence of immediate incentives for behavioral change. Our study is the first to quantify the relationship between sanitation facilities and NPSV in India and confirms the relevance of household sanitation facilities for women's safety as well as children's health.

Our study has some limitations. First, the data we use are from 2005-06, which unfortunately, are the most recent available data from India. Given the attention this topic has received and the fact that a new wave of data will not be available for at least another two years, we believe it is important to disseminate this information now, and that the new wave of data will only further confirm our findings. Second, we cannot assess a direct causal linkage between NPSV and toilet facilities because our data are cross-sectional; however, we establish temporal ordering by restricting our measures of NPSV in the last year among women who have resided in their current home for one year or more. Finally, we recognize that the intent of the DHS data collection was not to focus on domestic violence or sanitation, but are modules included in the survey. Thus the types of questions asked in these modules were limited in scope and depth, thus we are unable to ascertain detailed circumstances and consequences of NPSV.

\section{Conclusion}

Our results, which suggest that women who use open defecation have twice the odds of NPSV than women who use household toilets, indicate that infrastructure improvements can provide women with some level of protection against NPSV. Our findings provide further rationale for NGOs and the Indian government to expand sanitation programs, and raise new questions about the potentially protective role of sanitation facilities in other contexts beyond India.

\section{Abbreviations}

IPSV: Intimate partner sexual violence; MDG: Millennium development goals; NFHS: National family health survey; NPSV: Non partner sexual violence; SBM: Swachh Bharat Mission; TSC: Total sanitation campaign

\section{Acknowledgements}

Not applicable.

\section{Funding}

This research was supported in part by a NIA training grant to the Population Studies Center at the University of Michigan (T32 AG000221) where AJ and AW are postdoctoral research fellows. The role of this funding source was limited to training, and had no bearing on any aspect of the study.

\section{Availability of data and materials}

The datasets generated and/or analyzed during the current study are available in the Demographic and Health Survey repository, which are available after a short registration process at [http://dhsprogram.com/ data/new-user-registration.cfm] $]^{14}$

\section{Authors' contributions}

AJ conceived of the study, and AW and ESG helped conceptualize it further. AW conducted the data analysis with inputs from AJ and ESG. AW wrote the methods section, ESG wrote the results section, and AJ wrote the Introduction and Discussion. All authors contributed equally to writing and editing all sections of the paper.

\section{Competing interests}

The authors declare that they have no competing interests.

\section{Consent for publication}

Not applicable.

\section{Ethics approval and consent to participate}

We used publicly available secondary data for these analyses, thus did not require additional ethics approval or consent to participate. The data come from the Demographic and Health Surveys, the protocols of which have been reviewed and approved by the ICF International Institutional Review Board, in addition to IRB approval within India at the International Institute for Population Sciences.

\section{Author details}

'University of Michigan, 426 Thompson St, Ann Arbor, Ml 48104, USA ¿University of Southern California, 851 Downey Way, Los Angeles, CA 90089, USA.

Received: 9 March 2016 Accepted: 1 November 2016

Published online: 08 November 2016

\section{References}

1. WHO/UNICEF, Progress on sanitation and drinking water - 2015 update and MDG assessment. 2015. http://www.who.int/water_sanitation_health/ monitoring/jmp-2015-update/en/. Accessed November 122015.

2. Kapur, A. and S. lyer, Swachh Bharat Mission SBM (Gramin) Budget Briefs 2015-16. Budget Briefs, 2015;7(5):1-9.

3. Travasso, C., India is set to miss millennium development goal for improving sanitation. BMJ, 2014:348:3764

4. Mara D, et al. Sanitation and health. PLoS Med. 2010;7(11):1359.

5. Patil, S.R., et al., The Effect of India's Total Sanitation Campaign on Defecation Behaviors and Child Health in Rural Madhya Pradesh: A Cluster Randomized Controlled Trial. PLoS Med, 2014;11(8):1-16.

6. McCarthy, J., How A Lack Of Toilets Puts India's Women At Risk Of Assault, in NPR News. New Delhi, India. http://www.npr.org/sections/parallels/2014/06/ 09/319529037/indias-rape-uproar-ignites-demand-to-end-open-defecation. Accessed July 252015

7. Lennon S. In: WaterAid, editor. Fear and anger: Perceptions of risks related to seuxal violence against women linked to water and sanitation in Delhi, India. London: Sanitation and Hygiene Applied Research for Equity; 2011.

8. Mader P. Attempting the production of public goods through microfinance the case of water and sanitation. J Infrastructure Dev. 2011;3(2):153-70.

9. Corburn, J. and C. Hildebrand, Slum Sanitation and the Social Determinants of Women's Health in Nairobi, Kenya. J Environ Public Health, 2015;2015:1-7.

10. Fiasorgbor DA. Water and sanitation situation in Nima and Teshie, Greater Accra Region of Ghana. J Toxicol Environ Health Sci. 2013;5(2):23-8.

11. Sahoo KC, et al. Sanitation-related psychosocial stress: A grounded theory study of women across the life-course in Odisha, India. Soc Sci Med. 2015:139:80-9.

12. Winter, S.C. and F. Barchi. Access to sanitation and violence against women: evidence from Demographic Health Survey (DHS) data in Kenya. Int J Environ Health Res. 2016;26(3):291-305. 
13. Caruso BA, et al. Gender disparities in water, sanitation, and global health. Lancet. 2015;386(9994):650-1.

14. Sciences, I.I.F.P. and M. International. National Family Health Survey (NFHS-3), 2005-06: India: Volumes I and II. Mumbai: IIPS: International Institute for Population Sciences; 2007.

15. WHO, Global and regional estimates of violence against women: prevalence and health effects of intimate partner violence and nonpartner sexual violence. WHO, Editor. Geneva; World Health Organization (WHO): 2013.

16. Doron A, Jeffrey R. Open defecation in India. Econ Pol Wkly. 2014;XLIX(49):72-8.

17. Abrahams $\mathrm{N}$, et al. Worldwide prevalence of non-partner sexual violence: a systematic review. Lancet. 2014;383(9929):1648-54.

18. House S, et al. Violence, Gender \& WASH: A Practitioner's Toolkit - Making water, sanitation and hygiene safer through improved programming and services. London: WaterAid/SHARE; 2014. http://www.susana.org/en/ resources/library/details/2098. Accessed October 2015.

19. Sommer M, et al. Violence, gender and WASH: spurring action on a complex, under-documented and sensitive topic. Environment and Urbanization. 2014:27:105-16

20. Robinson, A.J., Scaling-Up Rural Sanitation in South Asia: Lessons Learned from Bangladesh, India, and Pakistan, in Water and Sanitation Program, South Asia. New Delhi; World Bank: Water and Sanitation Program- South Asia: 2005. p. 136

21. Coffey D, et al. Revealed preference for open defecation. Econ Pol Wkly. 2014;49(38):43

\section{Submit your next manuscript to BioMed Central} and we will help you at every step:

- We accept pre-submission inquiries

- Our selector tool helps you to find the most relevant journal

- We provide round the clock customer support

- Convenient online submission

- Thorough peer review

- Inclusion in PubMed and all major indexing services

- Maximum visibility for your research

Submit your manuscript at www.biomedcentral.com/submit 